
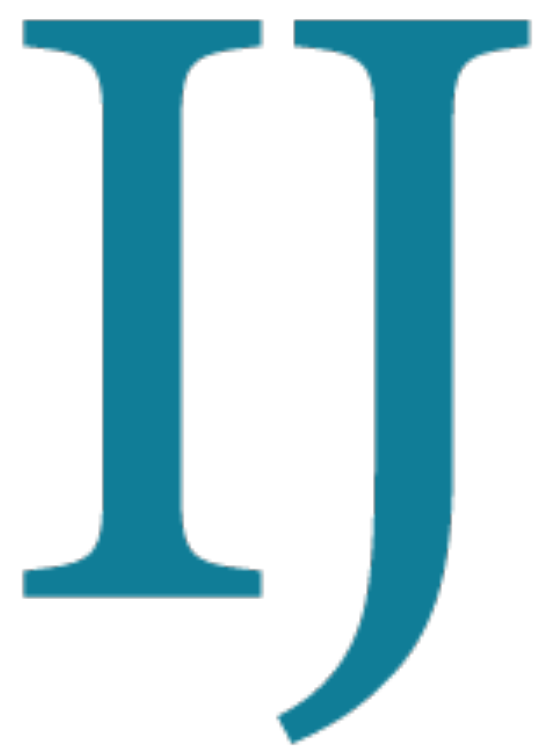

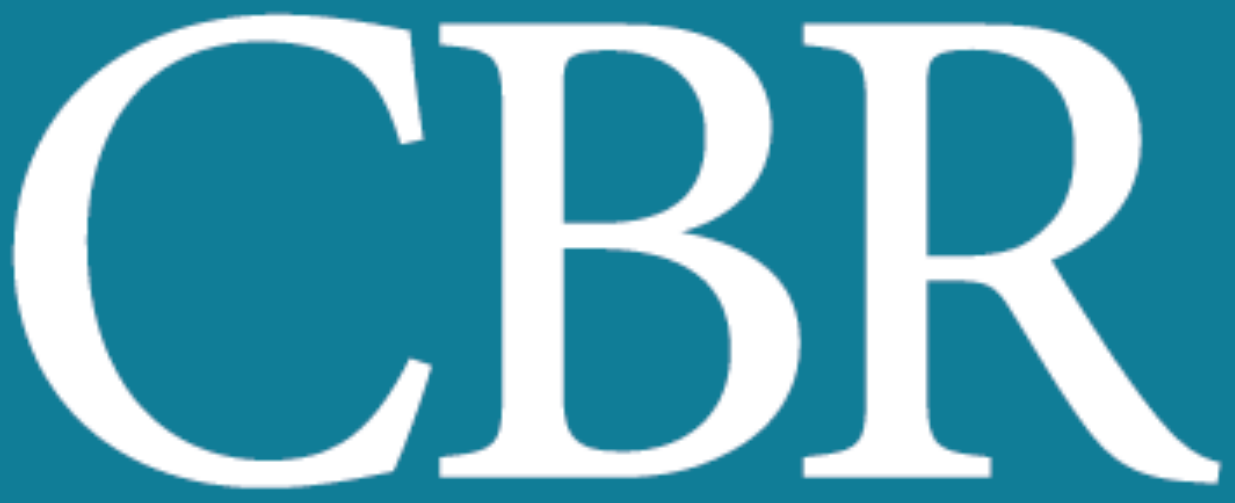

INTERNATIONAL JOURNAL OF CANCER AND BIOMEDICAL RESEARCH

https://jcbr.journals.ekb.eg

Editor-in-chief

Prof. Mohamed Labib Salem, $\mathrm{PhD}$

Potential Protective Effects of Sildenaffl and Moringa on Experimentally-induced Gastric Ulcer in Rats

Raghda El Mahdy, Sally Risha, Aladin Sisi, Walied Sobhy 


\section{International Journal of Cancer \& Biomedical Research \\ (IJCBR) https://jcbr.journals.ekb.eg}

IJCBR is an Int. journal published by the Egyptian Society of Cancer Research (EACR, established in 2014, http://eacr.tanta.edu.eg) and sponsored by the Egyptian Knowledge Bank (EKB: www.ekb.eg).

IJCBR has been approved by the Supreme Council of Universities, Egypt with score 7 (http://egjournal.scu.eg). The journl is cited by google scholar and registered by Publons (https://publons.com). The journal has recently been evaluated in 2020 by Nature Springer with a good standing.

\section{Scope of IJCBR}

- Drug discovery from natural and synthetic resources

- BioMedical applications of nanotehnology

- Sem cell biology and its application

- Basic and applied biotechnology

- Inflammation and autoimmune diseases

- In slico models and bioinformatics

- In vitro and In vivo preclinical animal models

- Cellular and molecular cancer biology

- Cancer Immunology and Immunotherapy

- New methods for prediction, early detection, diagnosis prognosis and treatment of dieases.

- Immunology in health and dieases

- Anti-microbial defense mechanisms

- Cellular and molecular physhiology and pahthology of diseases

\section{IJCBR Editor,}

Prof. Mohamed Labib Salem, PhD

Professor of Immunology

Faculty of Science, Tanta Universiy, Egypt 


\title{
Potential Protective Effects of Sildenafil and Moringa on Experimentally-induced Gastric Ulcer in Rats
}

\author{
Raghda El Mahdy ${ }^{1}$, Sally Risha ${ }^{1}$, Aladin Sisi ${ }^{1}$, Walied Sobhy ${ }^{2}$ \\ ${ }^{1}$ Department of Pharmacology, Faculty of pharmacy, Tanta University, Egypt \\ ${ }^{2}$ Faculty of Veterinary Medicine, Kafrelsheikh University, Egypt.
}

\section{IIII}

ABSTRACT

BACKGROUND: Sildenafil and Moringa appear to have the ability to reduce the ulcerogenic effect of the drugs used to induce ulcer in rats. AIM: The present study was conducted to investigate the gastroprotective effects of sildenafil citrate, Moringa oleifera, which is an Indian plant, and their combination against an indomethacininduced gastric ulcer in rats. MATERIALS AND METHODS: Gastric ulcers were induced by oral administration of indomethacin. Forty rats were used in the study, divided into 5 groups: Control Vehicle (Group 1), group 2 received indomethacin $(100 \mathrm{mg} / \mathrm{kg})$ P.O., group 3 was pretreated with sildenafil $(50 \mathrm{mg} / \mathrm{kg})$ P.O. and then received indomethacin, group 4 was pretreated with Moringa leaf powder $(200 \mathrm{mg} / \mathrm{kg})$ and then received indomethacin, group 5 received both sildenafil and Moringa before administration of indomethacin. RESULTS: Indomethacin induced marked ulceration in the gastric mucosa and an increase in gastric acidity as compared to the vehicle control group. Furthermore, the indomethacin group exhibited an increased lipid peroxide (MDA) and tumor necrosis factor- $\alpha$ (TNF- $\alpha$ ) tissue contents, while a decreased content of nitric oxide (NO). Pretreatment with sildenafil and/or Moringa significantly reduced the gastric acid secretion, ulcer score, tissue MDA and TNF- $\alpha$ contents and increased NO content compared with indomethacin alone. CONCLUSION: Both Sildenafil and Moringa have a protective effect on the experimentally induced gastric ulcer.

Keywords: Sildenafil; Moringa, Gastric ulcer; NO; TNF- $\alpha$; Apoptosis

Editor-in-Chief: Prof. M.L. Salem, PhD - Article DOI: 10.21608/jcbr.2020.20714.1007

\section{Article history}

Received: December 8, 2019 Revised: March 3, 2020 Accepted: March 13, 2020

Correspondence to:

Dr. Raghda El Mahdy, PhD Department of Pharmacology, Faculty of Pharmacy, Tanta University, Egypt Tel:

Email:

\section{INTRODUCTION}

Gastric mucosal damage is a familiar disorder of the gastrointestinal system. The pathogenesis of gastric ulcers is based on complex interactions between protective and aggressive factors (Karakaya et al., 2009). When the aggressive factors like gastric acid, pepsin and reactive oxygen species (ROS) overwhelm protective factors such as adequate mucosal blood flow, the mucosal bicarbonate barrier, endothelial cell regeneration and continuous prostaglandin production, this unbalance can lead to the generation of ulcers (Li et al., 2006). Moreover, many otherwise beneficial therapies, including low-dose aspirins, dual antiplatelet therapy and non-steroidal antiinflammatory drugs (NSAIDs) such as indomethacin, are important risk factors for recurrent ulcers and related complications (Tang and Chan, 2012). 
Consumption of NSAIDs is shown to be related to increased mucosal injury, erosions and gastric and duodenal bleeding. This effect is mainly due to the inhibition of the cyclooxygenase. The cyclo-oxygenase enzymes: COX-1 and COX-2 play an important role in mucosal defense. COX-1 is critical to the synthesis of prostaglandins such as prostacyclin $\left(\mathrm{PGI}_{2}\right)$ and $\left(\mathrm{PGE}_{2}\right)$ that have protective effects for the gastric mucosa, i.e. they maintain gastric blood flow, turnover of mucosal cells and the synthesis and secretion of mucus (Pawlik et al., 2002). COX-2 inhibits leukocyte adherence and also helps to maintain gastric blood flow (Wallace et al., 2000). So the inhibition of cyclooxygenase enzymes has sufficient a critical role in the process of gastric ulcer. Evidence has been produced that leukocyte adherence to the vascular endothelium, superoxide radicals and protease liberation may be relevant pathogenic mechanisms in NSAIDs gastropathy (Wallace, 1997).

There are a lot of anti-ulcerogenic drugs, among which the most effective are the proton pump inhibitors. However, these drugs do not always provide an effective treatment of ulcer. Therefore, treatment of ulcers is still an important problem, and new drugs are still needed for the treatment of gastric ulcers.

Sildenafil citrate (SC) is currently used in the treatment of functional impotence it increases the effect of the cyclic guanosine 3', 5' monophosphate (cGMP), which displays an inhibitory effect on the smooth muscle cells of the arterioles supplying the human corpus cavernosum. The effect of SC is due to blockade of the phosphodiesterase type 5, which inactivates the intracellular cGMP stimulated by nitric oxide (NO) (Bortolotti et al., 2001). Diminished mucosal circulation has been blamed as one of the etiological factors in gastric ulcer formation. Like prostaglandins, the L-Arginine/nitric oxide (NO) pathway is a major protective system in gastric mucosa via relaxation of the arterial smooth muscles. Inhibition of nitric oxide synthase aggravates the injury in animal models of gastric ulcers (Konturek et al., 1993).

Moringa oleifera Lamm (Family: Moringaceae), is also known as the drumstick tree and horseradish tree, is indigenous to Northwest India, Pakistan, Bangladesh, and Afghanistan (Lambole and Kumar, 2012). This tree is the most widely cultivated species of the genus Moringa. Leaves of $M$. oleifera are highly nutritious, being a significant source of $\beta$ carotene, vitamin $C$, protein, iron, and potassium (Pal et al., 1995). Almost all parts of this plant root, leaves, fruit, bark, seeds, and flowers are reported to have important medicinal values as cardiac and circulatory stimulants and to have antitumor, antipyretic, anti-inflammatory, antihypertensive, diuretic, cholesterol-lowering, antioxidant, antispasmodic, antibacterial, and antifungal activities (Mehta et al., 2011; Bichi et al., 2012). Moreover, the ethanolic extract of leaves of $M$. oleifera is reported to have antiulcer activity (Verma et al., 2012). In this study, we investigated the gastroprotective effect of sildenafil and the powdered leaves of $M$. oleifera on gastric ulcer and the effect of their combination together.

\section{MATERIAL AND METHODS DRUGS}

Indomethacin (INDO) was obtained as a gift from Kahira Pharmaceuticals and Chemical Industries Co. (Cairo, Egypt). Sildenafil was purchased from Pfizer (Cairo, Egypt) and Moringa was collected from Botanical Gardens (Sadat city, Egypt).

\section{ANIMALS}

Wistar male rats (males, 170-200g, 12-week age) were obtained from the National Research Center (Giza, Egypt). The rats were housed in wire cages in a pathogen-free facility maintained at $24 \pm 2 \circ \mathrm{C} ; 60-70 \%$ relative humidity and a $12: 12 \mathrm{~h}$ light: dark cycle. All rats had ad libitum access to standard rodent chow and filtered tap water. All rats were acclimatized for one week before the experiments. This study was conducted following the guidelines for the care and use of laboratory animals and approved by the Research Ethics Committee of Faculty of Pharmacy, Tanta University (Tanta, Egypt). All rats fasted $24 \mathrm{~h}$ before experiments and allowed free access to tap water. Rats were kept in wide wire mesh-bottom cages to avoid coprophagy; 
water access was prevented for $2 \mathrm{~h}$ before the drug's dosing.

For the study design, the rats were randomly divided into five groups $(n=8)$ :

1. Group 1 received $1 \mathrm{ml}$ of $1 \%$ sodium carboxymethylcellulose (CMC) by oral gavage only.

2. Group 2 received indomethacin $(100 \mathrm{mg} /$ kg body weight) dissolved in 1\% (CMC) P.O. for induction of ulcer (Araujo et al., 2011).

3. Group 3 was pretreated with Sildenafil $(50 \mathrm{mg} / \mathrm{kg}$ ) (Kiziltunç et al., 2007) dissolved in $1 \%$ CMC P.O. and after $30 \mathrm{~min}$ received the dose of indomethacin.

4. Group 4 pretreated with Moringa powder (prepared by grinding leaves) dissolved in $1 \% \mathrm{CMC}$ in a and administered in the dose $(200 \mathrm{mg} / \mathrm{kg})$ and after 2 hours the rats received the dose of indomethacin (Mbikay, 2012).

5. Group 5 received Moringa $(200 \mathrm{mg} / \mathrm{kg}$ ) then after one-hour and a half, received sildenafil (50mg/kg). After another $30 \mathrm{~min}$, they received indomethacin dose.

Six hours after the INDO administration, rats were anesthetized in a jar with a tight-fitting lid containing an appropriate amount of ether and sacrificed by cervical dislocation. The stomach was opened and conducted to macroscopically, biochemical and histopathological analysis.

In all cases, the stomach of each rat was excised, opened along the greater curvature and all the gastric juice was collected. Thereafter, the tissue was rinsed in $0.9 \%$ saline. The excised stomach was then cut into two halves; one half was immediately fixed in $10 \%$ buffered formalin, while the remainder was cut into pieces, weighed and stored at $-80 c^{\circ}$ for later use in the various assays outlined below.

\section{Histopathological and immunohistochemical Investigation}

Samples from the fundus of the stomach were collected from animals of different groups. The samples were fixed in $10 \%$ neutral buffered formalin, dehydrated in alcohol, cleared in xylene, embedded in paraffin and sectioned in 5 $\mu \mathrm{m}$ thickness. The serial sections were subjected to staining with hematoxylin and eosin (Suvarna and Layton, 2013). The immunohistochemical staining was done according to Sameh et al. (2019). The serial sections were dewaxed, hydrated, and immersed in an antigen retrieval (EDTA solution, $\mathrm{pH}$ 8). They were then treated with hydrogen peroxide $0.3 \%$ and protein block, followed by incubation with caspase 3 primary antibody (RandD Systems Inc., Minneapolis, Minn, USA; 1:100 dilution). The slides were rinsed three times with PBS, incubated with anti-mouse IgG secondary antibodies (EnVision + System HRP; Dako) for 30 minutes at room temperature, visualized with di-aminobenzidine commercial kits (Liquid DAB+Substrate Chromogen System; Dako), and finally counterstained with Mayer's haematoxylin. As a negative control, the primary antibody was replaced by normal mouse serum. The labelling index of caspase-3 was expressed as the percentage of positive cells per total of 1000 counted cells in about 8 to 10 high power fields.

\section{Ulcer Depth}

The depth of ulcer was measured using ImageJ analysis software (NIH, USA) from the center of the ulcer surface.

\section{Measurement of gastric $\mathrm{pH}$}

Each stomach obtained was opened along the greater curvature and the gastric content was drained into a centrifuge tube, then centrifuged at $1000 \mathrm{rpm}$ for $10 \mathrm{~min}$ at 4 으, the clear supernatant was recovered (Sivaraman and Muralidharan, 2011) and $1 \mathrm{ml}$ of it was diluted with $1 \mathrm{ml}$ of distilled water, and $\mathrm{pH}$ of the solution was measured using $\mathrm{pH}$ meter (HANNA ${ }^{\circledR}$ benchtop $\mathrm{pH}$ meters, HI 110, USA) (Dashputre and Naikwade, 2011).

\section{Measurement of ulcer index and ulcer score}

After gastric contents were removed, the total stomach samples were evaluated under magnification (in a blinded manner). Based on these evaluations, the ulcer score for each group was calculated as the mean number of ulcers/stomach/rat in each group. From these values, an Ulcer Index (UI) was calculated by multiplying each group's ulcer score $\times 100$. Subsequently, the net preventive index was calculated as $100 \% \times$ (UI of ulcer only group-UI of the treated group)/UI of the ulcerated only group (Dawud et al., 2014). After these analyses, the tissues were then processed for use in the various assays outlined below. 


\section{Measurement of Nitric oxide (NO) content}

Samples of isolated tissues (100mg) were homogenized in $10 \mathrm{vol}$ ice-cold saline solution using a PT 3100 Polytron homogenizer (Kinematica instruments, Lucerne, Switzerland) (Miranda et al., 2001). Upon disruption, absolute ethanol was added (2:1 volume ratio) to precipitate all proteins. After allowing materials to separate over a $15 \mathrm{~min}$ period at $25^{\circ} \mathrm{C}$, the supernatant was recovered. To $0.5 \mathrm{ml}$ supernatant, $0.5 \mathrm{ml}$ vanadium chloride $(8 \mathrm{mg}$ $\mathrm{VCl} / \mathrm{ml}$ ) was added, rapidly followed by addition of $0.25 \mathrm{ml}$ of $2 \%$ sulfanilamide and $0.25 \mathrm{ml}$ of $0.1 \% \quad \mathrm{~N}$-(1-naphthyl)-ethylene diamine. The mixture was then vortexed and incubated at $370 \mathrm{C}$ for $30 \mathrm{~min}$ before its absorbance was measured at $540 \mathrm{~nm}$ in a Model UV-1601 PC spectrophotometer (Shimadzu, Kyoto, Japan). Sodium nitrite was dissolved in distilled water and serial dilutions were prepared; $0.5 \mathrm{ml}$ of each dilution was used in place of tissue extract and processed as above. Values of NO in each sample were then determined by extrapolation from the prepared standard curve.

\section{Determination of malondialdehyde (MDA) content}

The method of Yoshioka et al. (1979) was adopted. $100 \mathrm{mg}$ of the stomach was washed with sodium chloride solution (0.9\%) and homogenized in 10 volumes of ice-cold potassium chloride solution (1.15\%) using polytron homogenizer (PT3100). To $0.5 \mathrm{ml}$ of the homogenate, $3 \mathrm{ml}$ of TCA $(0.5 \%)$ and $1 \mathrm{ml}$ $\operatorname{TBA}(0.6 \%)$ were added, mixed and then the mixture was heated for $45 \mathrm{~min}$ in a boiling water bath. After cooling, $4 \mathrm{ml}$ of $\mathrm{n}$-butanol was added and mixed forcefully. The $n$-butanol layer was separated by centrifugation at $3000 \mathrm{rpm}$ for $15 \mathrm{~min}$. The absorbance of the pink-colored product was measured at $535 \mathrm{~nm}$ against a blank containing water instead of the sample, using double beam spectrophotometer (Shimadzu, UV-PC160, Japan).

\section{Measurement of Tumor necrosis factor (TNF $\alpha$ ) content}

Tumor necrosis factor-alpha (TNF- $\alpha$ ) in the stomach was measured by ELISA according to Chen et al. (1994), using the kit provided by AssayPro, USA. $100 \mathrm{mg}$ of the stomach were homogenized in 10 volumes of ice-cold
Phosphate buffered saline (PBS). The samples were centrifuged at $3000 \mathrm{rpm}$ for $10 \mathrm{~min}$ and the supernatant was used for ELISA assay. 50 $\mathrm{ll}$ of rat TNF- $\alpha$ standard or samples were added then wells were covered with sealing tape and incubated for 2 hours. Wells were washed five times with wash buffer. $50 \mu$ l of biotinylated rat TNF- $\alpha$ antibody were added to each well and incubated for 2hours. $50 \mu \mathrm{l}$ of streptavidinperoxidase conjugate was added and incubated for $30 \mathrm{~min}$; wells were then washed. $50 \mu \mathrm{l}$ of chromogen substrate was added to each well and incubated for approximately $20 \mathrm{~min}$ or till the optimal blue-color density develops. 50 $\mathrm{\mu l}$ of stop solution were added to each well accurately. The color will change from blue to yellow. The absorbance was measured at $450 \mathrm{~nm}$ using a microplate reader (Labnics LMR9602).

\section{Statistical analysis}

Results were expressed as mean \pm SD. Regression analysis and correlation were done for standard curves. The comparison among groups was carried out by using one-way analysis of variance (ANOVA). Planned comparisons between the different groups were done using post-hoc analysis. If $P<0.05$, this indicates a significant difference. GraphPad prism 5.0 Demo (Graph-Pad software, San Diego, CA) was used for statistical analysis of different groups.

\section{RESULTS}

\section{Effect on gastric $\mathrm{pH}$}

INDO caused significant decreases $(P<0.05)$ in gastric $\mathrm{pH}$; the change was by $29.11 \%$ compared to the $\mathrm{pH}$ of juice from rats in the control group. Pre-treatment with sildenafil, Moringa and their combination significantly $(P<0.05)$ increased gastric $\mathrm{pH}$ compared to indomethacin ulcerated group by $77.16 \%, 51.70 \%$ and $70.84 \%$ respectively (Figure 1).

\section{Effect on ulcer index and preventive index}

The ulcerated (INDO) group had an ulcer score of $26.125 \pm 5.3835 /$ stomach and UI of 2612.5 (Table 1). Rats that had been treated with sildenafil, Moringa and their combination before INDO showed significant improvements (i.e. decreases) in ulcer scores $(P<0.05)$ compared to indomethacin group. 


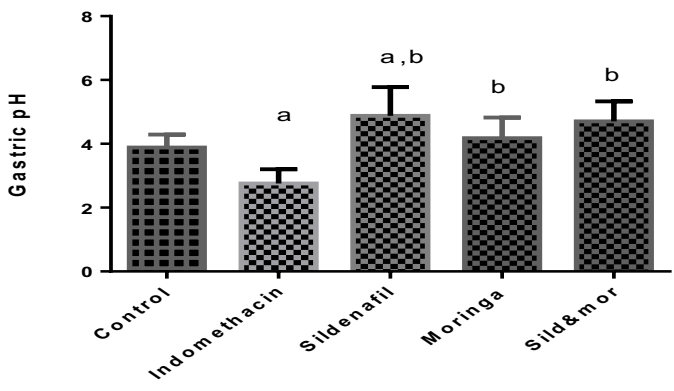

Figure 1: Effect of different treatments on gastric $\mathrm{pH}$. Data shown are mean $\pm S D$ ( $n=8$ rats/group). (a) Expresses significant differences between the control and the rest of the groups $(P<0.05)$. (b) Expresses significant differences between the induced ulcer and the treated groups $(P<$ 0.05).

Rats in the sildenafil group had a mean score of $4.75 \pm 1.488$ /stomach, while those in Moringa group had a value of $14.375 \pm 3.4615 /$ stomach and those in Moringa and sildenafil combination group had a value of $6.625 \pm 2.559$ / stomach Based on the calculated preventive index, sildenafil appeared to have imparted the greatest gastroprotective effect, with these rats having a group UI of 475 and a net preventive index of $81.81 \%$. In comparison, rats in the Moringa regimen had a group UI of 1437.5 and a net preventive index of $44.97 \%$ and rats in the combination regimen had a group of UI of 662.5 and a net preventive index of $74.64 \%$ (Table 1 ).

Table 1: Effect of different treatments on ulcer index

\begin{tabular}{llll}
\hline Group & Ulcer score & $\begin{array}{l}\text { Ulcer } \\
\text { index }\end{array}$ & $\begin{array}{l}\text { preventive } \\
\text { index }\end{array}$ \\
\hline Conrol & - & - & - \\
Indomethacin & $26.125 \pm 5.38$ & 2612.5 & 0 \\
Sildenafil & $4.75 \pm 1.488^{\mathrm{a}}$ & 475 &.$\% 81.81$ \\
Moringa & $14.375 \pm 3.46^{\mathrm{a}}$ & 1437.5 & $\% 44.97$ \\
Sildenafil and & $6.625 \pm 2.55^{\mathrm{a}}$ & 662.5 & $\% 74.64$ \\
Moringa & & & \\
combination & & & \\
\hline
\end{tabular}

Data shown are mean $\pm S D$ ( $n=8$ rats/group). (a) Expresses significant differences between the indomethacin group and the rest of the groups $(P<0.05)$.

\section{Effect on gastric nitric oxide content}

INDO significantly decreased gastric tissue NO content $(P<0.05)$ by $43.96 \%$ compared to the level of NO in tissues of rats in the control group. Pre-treatment with sildenafil, Moringa and their combination significantly $(P<0.05)$ increased gastric NO levels by $95.32 \%, 80.41 \%$ and $120.96 \%$, respectively compared to the level of NO in tissues of rats in indomethacin Group. Pre-treatment with the combination of sildenafil and Moringa induced higher $(P<0.05)$ NO compared to Moringa treatment only.

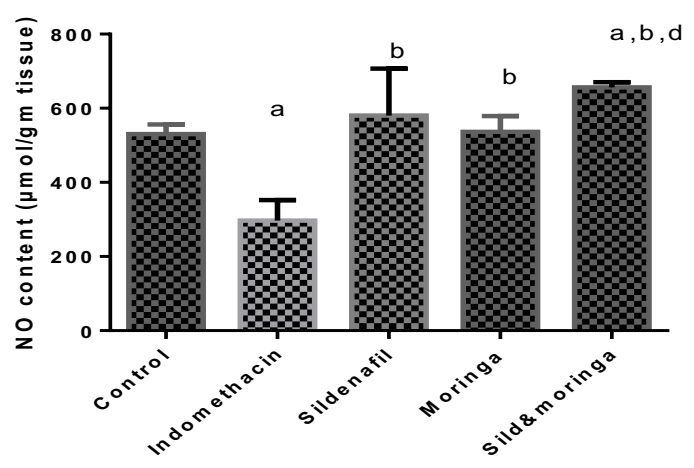

Figure 2: Effect of treatments on gastric nitric oxide content. Data shown are mean $\pm S D$ ( $n=8$ rats/group). (a) Expresses significant differences between the control and the rest of the groups $(P<0.05)$. (b) Expresses significant differences between the induced ulcer and the treated groups $(P<0.05)$. (c) Expresses a significant difference between sildenafil groups only $(P<0.05)$. (d) Expresses a significant difference between Moringa groups only $(\mathrm{P}<$ 0.05).

\section{Effect on gastric MDA content}

INDO caused a significant $(P<0.05)$ increase in gastric MDA contents by $50.66 \%$ compared to values in tissues from the normal control rats. Pretreatment with sildenafil, Moringa and their combination decreased $(P<0.05)$ gastric MDA levels significantly by $26.58 \%, 41.97 \%$ and $28.79 \%$, respectively compared to the level of MDA in tissues of rats in indomethacin group and had no significant effect on MDA levels compared to control group (Figure 3).

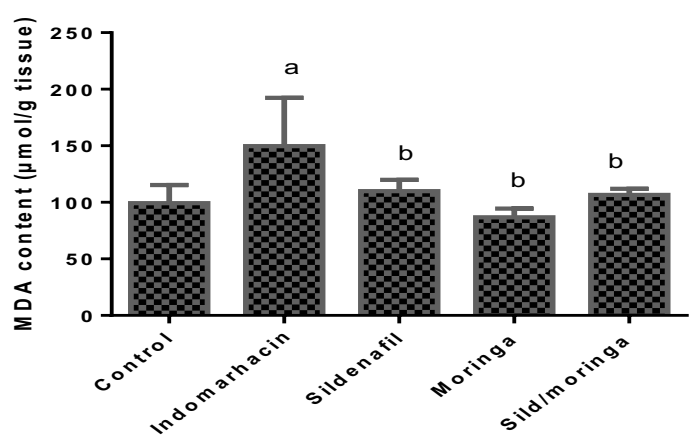

Figure 3: Effect of treatments on malondialdehyde content. Data shown are mean $\pm S D$ ( $n=8$ rats/group). (a) Expresses significant differences between the control and the rest of the groups $(P<0.05)$. (b) Expresses significant differences between the induced ulcer and the treated groups $(P<0.05)$. 


\section{Effect on gastric TNF $-\alpha$ content}

INDO alone caused a significant $(P<0.05)$ increase in gastric TNF- $\alpha$ contents by 99.54\%compared to values in samples from the normal control rats (Figure 4). Sildenafil, Moringa and their combinations treatment significantly $(\mathrm{P}<0.05)$ decreased gastric TNFalevels by $34.20 \%, 49.65 \%$ and $48.17 \%$, respectively compared to levels seen in the ulcer (INDO only) rats (Figure 4).

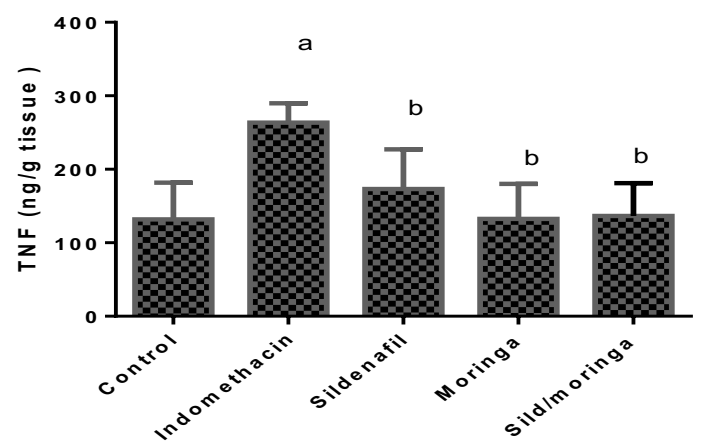

Figure 4: Effect of treatments on gastric TNF- $\alpha$ content. Data shown are mean $\pm S D$ ( $n=8$ rats/group). (a) Expresses significant differences between the control and the rest of the groups $(P<0.05)$. (b) Expresses significant differences between the induced ulcer and the treated groups $(P<$ 0.05).

\section{Histopathology and Immunohistochemistry of caspase-3}

The histopathological sections of different treated groups were illustrated in (Figure 5a-d). Fundic gastric portion of control animal showed normal gastric glands with normal epithelial lining. The diseased animal revealed diffuse and deep ulcers associated with marked sloughing of the mucosal surface and submucosal inflammatory cells infiltration mostly mononuclear cells consisted of lymphocytes, macrophages and mast cells in addition to neutrophils. Diseased animal pretreated with Moringa powder showed limited degenerative changes to the covering mucosal lining of mostly the gastric pits. The stomach of diseased animal pretreated with sildenafil showed a decrease in the degenerative changes within the gastric glands. The stomach of diseased animal pretreated with a combination of both Moringa and sildenafil revealed a marked decrease of degeneration of the gastric glands and mostly were near to normal limits of the histological gastric structures.
Regarding caspase 3 IHC (Figure 5A-D), gastric mucosa of control group revealed scanty expression. While the gastric mucosa of indomethacin-treated animal showed marked expression within the sloughed necrotic and/or degenerated gastric glands lining epithelium. The gastric mucosa of indometh+moringa revealed localized expression of caspase 3 within the mucosal surface. The gastric mucosa of indometh+sildenafil showed decrease caspase 3 expressions. Interestingly, gastric mucosa of the combination group demonstrated a marked decrease of caspase 3 immunostaining. Quantitative scoring of caspase 3 revealed a marked increase of immunolabelling index when treated with Indomethacin. However, pretreatment with a single administration of Moringa or sildenafil or their combination decreased caspase $3(P<$ 0.05 ) significantly (Figure 6).

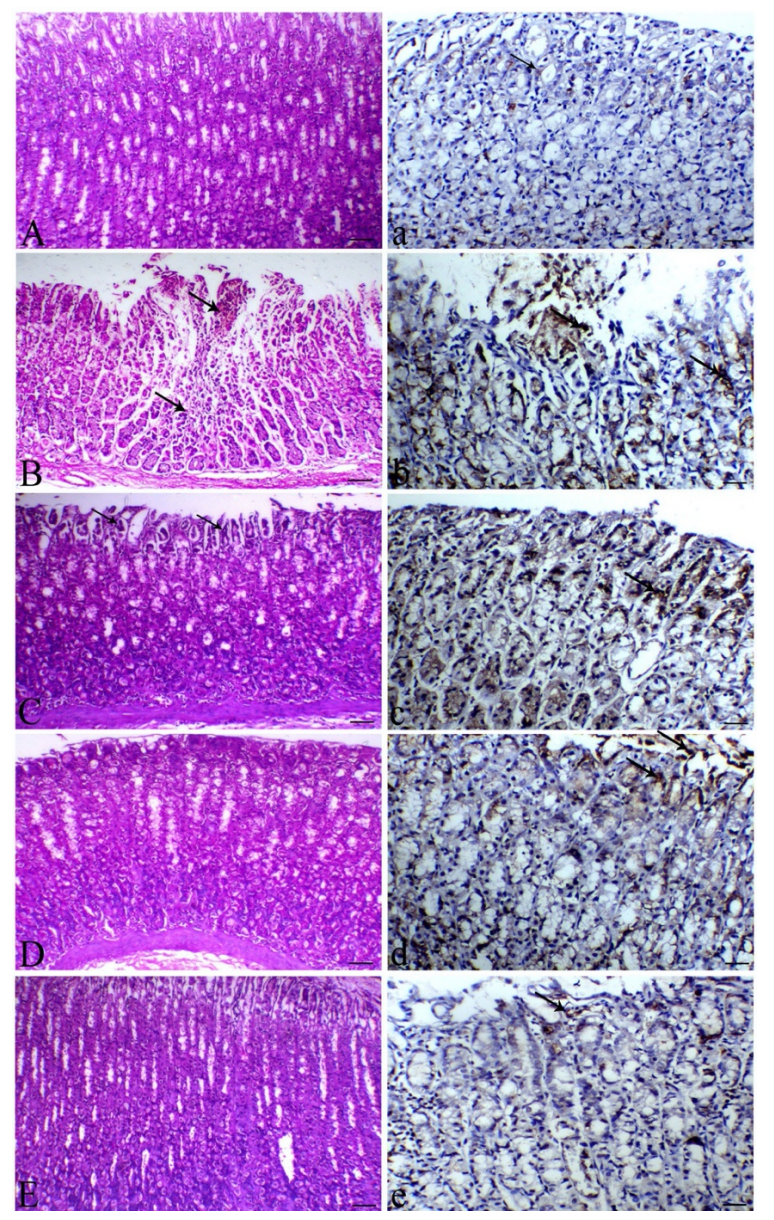

Figure 5: Representative photomicrograph of the gastric sections of different treated groups. H\&E result is illustrated in capital letters, bar $=100 \mu \mathrm{m}$. (A) stomach of the normal animal showed normal mucosal lining. (B) stomach of indomethacin-treated animal revealed ulcer 
formation associated with necrosis and sloughing of the gastric mucosa (arrows). (C) stomach of diseased animal treated with Moringa powder revealed degenerative changes within the covering mucosal lining of mostly the gastric pits (arrows). (D) stomach of diseased animal treated with sildenafil showed degenerative changes within the gastric glands. (E) stomach of diseased animal treated with the combination of both Moringa and sildenafil revealed a marked decrease of degeneration of the gastric glands and mostly were near to normal limits of the histological gastric structures. Caspase $3 \mathrm{IHC}$ result is entitled with small letters, bar $=50 \mu \mathrm{m}$. (a) gastric mucosa of control group revealed scanty expression. (b) gastric mucosa of indomethacin-treated animal showed marked expression within the sloughed necrotic and/or degenerated gastric glands lining epithelium. (c) gastric mucosa of indometh+moringa revealed localized expression within the mucosal surface (arrows). (d) gastric mucosa of indometh+sildenafil showed decrease caspase 3 expression (e) gastric mucosa of indomethacin + sildenafil + Moringa showed a marked decrease of caspase 3 immunostaining.

The depth of ulcer was measured using Image J analysis software (NIH, USA) from the center of the ulcer surface. Quantitative scoring of ulcer depth revealed significantly $(P<0.05)$ increase of the ulcer depth in indomethacin group compared to the control group. The depth of ulcer significantly $(P<0.05)$ decreased in a single administration of Moringa or sildenafil ( $P$ $<0.05)$ and markedly decreased with the combination of both agents $(P<0.05)$ (Figure 7$)$.

\section{Caspase 3 LI \%}

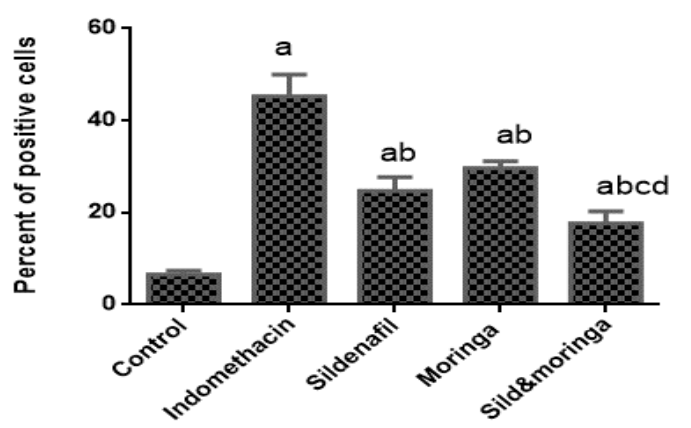

Figure 6: Effect of treatments on Caspase 3 LI\%. Data shown are mean $\pm S D$ ( $n=8$ rats/group). (a) Expresses significant differences between the control and the rest of the groups $(P<0.05)$. (b) Expresses significant differences between the induced ulcer and the treated groups $(P<$ 0.05). (c) Expresses a significant difference between sildenafil groups only $(P<0.05)$. (d) Expresses a significant difference between Moringa groups only $(P<0.05)$.

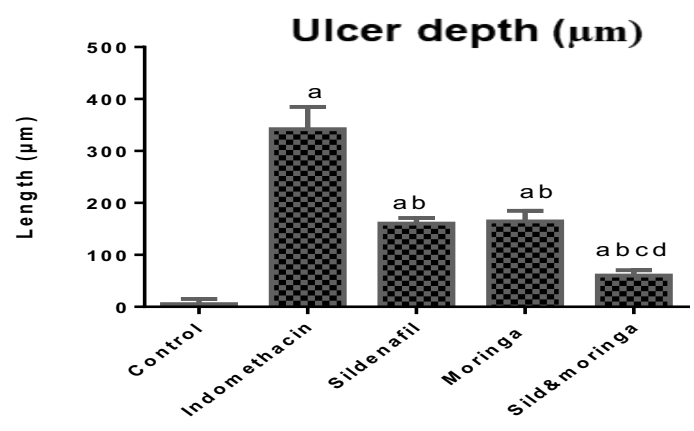

Figure 7: Effect of treatments ulcer depth. Data shown are mean $\pm S D$ ( $n=8$ rats/group). (a) Expresses significant differences between the control and the rest of the groups $(P<0.05)$. (b) Expresses significant differences between the induced ulcer and the treated groups $(P<0.05)$. (c) Expresses a significant difference between sildenafil groups only $(P<0.05)$. (d) Expresses a significant difference between Moringa groups only $(P<0.05)$.

\section{Discussion}

Despite the great progress in the treatment protocols, peptic ulcers are still a major ongoing health problem. The gastric barrier prevents the damage of mucosa deeper structures by noxious substances. Mucosal microcirculation of the stomach has an important role in gastric mucosal protection (Bou-Abboud et al.,1988).

The use of NSAIDs is considered to be the major risk factor in gastric ulcers. The mechanisms suggested for the gastric damage caused by NSAIDs are inhibition of prostaglandin synthesis and inhibition of epithelial cell proliferation in the ulcer margin, which is critical for the reepithelization of the ulcer crater (Levi et al., 1990). Prostaglandin is a key player in the protection of gastric mucosal integrity by increasing local blood flow and promoting synthesis and secretion of mucus and bicarbonate (Cryer and Mahaffey, 2014). NSAIDs disrupt mucus phospholipids and lead to the uncoupling of mitochondrial oxidative phosphorylation, thus initiating mucosal damage. When exposed to acidic gastric juice $(\mathrm{pH} 2)$, NSAIDs turned to protonated form and cross lipid membranes to enter epithelial cells ( $\mathrm{pH}$ 7.4), where they ionize and release $\mathrm{H}+$ so cannot cross the lipid membrane, and are trapped in epithelial cells, leading to the uncoupling of oxidative phosphorylation, decreased mitochondrial energy production, increased cellular permeability, and reduced cellular integrity (Kuna et al., 2019). 
In the present study, indomethacin, caused a significant increase in ulcer index, gastric juice acidity. The ulceration induced by indomethacin is conducted by various processes, including generation of reactive oxygen species, initiation of lipid peroxidation, infiltration of leukocytes, induction of apoptosis, and inhibition of prostaglandin synthesis (Bech et al., 2000). Decreased prostaglandin level destroys almost all aspects of gastroprotection and increases acid secretions which, in turn, aggravate the ulcer (Miller, 1983).

Indomethacin increases vascular permeability, an effect that depends at least partially on the activated neutrophils that recruit into the gastric microcirculation and the increased formation of oxygen radicals (Naito et al.,1993), factors that are considered important prime events that lead to gastric mucosal injury. The source of oxygen free radicals is multifaceted and it includes the indomethacin-induced infiltration of activated polymorphonuclear neutrophils (Vaananen et al., 1991; Tanaka and Yuda, 1996) and/or mitochondrial dysfunction (Mahmud et al., 1996; Pastoris et al., 2008).

Tumor necrosis factor (TNF- $\alpha$ ) is a proinflammatory cytokine secreted by macrophages increasingly during ulcerative stress (Hamaguchi et al., 2001), it is a potent stimulator of polymorphonuclear neutrophil infiltration into gastric mucosa (Wei et al., 2003), through up-regulating the expression of adhesion molecules in both neutrophil and endothelial cells (Santucci et al., 1995). Overproduction of TNF- $\alpha$ induces the incidence of gastric ulcer and cancer (Mitsushige et al., 2007). In this study indomethacin significantly increased gastric TNF- $\alpha$ content as compared to the vehicle control group. This finding coincided with the finding of Appleyard et al. (1996), who reported that indomethacin up-regulated the synthesis of pro-inflammatory molecules like TNF- $\alpha$ contributing to mucosal injury. Moreover, Swarnakar et al. (2005) found that indomethacin-induced gastric TNF- $\alpha$ content upregulation at the ulcer site seemed mostly to be responsible for ulcerogenesis. Probably, prostaglandins inhibition by NSAIDs is responsible for the TNF- $\alpha$ rise, as these classes of drugs markedly reduce prostaglandin synthesis, which was known to be potent inhibitors of TNF- $\alpha$ release from both macrophages (Kunkel et al., 1986). The upregulatory action of indomethacin to gastric TNF- $\alpha$ is possibly responsible for the decrease in mucosal NO. This action is in agreement with the results of Bauer et al. (1997), who recorded that TNF- $\alpha$ is a potent inhibitor to constitutive $\mathrm{NO}$, which mediated a protective effect in the stomach, mostly through modulation of cytokine production.

Nitric oxide (NO) is an endogenous defensive agent for gastric cells and exhibits gastroprotective effects against different types of aggressive agents (Samini et al., 2002). It is involved in the maintenance of mucosal integrity through the regulation of mucus and alkaline secretion, gastric motility and microcirculation (Tsukimiand Okabe, 2001). NO is known to modulate acid levels, gastric mucus secretion, and blood flow in gastric tissues (Martín et al., 2001). NO has also been reported to prevent membrane lipid peroxidation (Hogg and Kalyanaraman, 1999); it may protect against NSAID damage by the promotion of prostaglandin synthesis (Salvemini et al., 1993).

In the present study, indomethacin significantly reduced gastric mucosal NO level compared to the control group. Tripp and Tepperma (199) reported a decrease in NO biosynthesis, as a result of decreased nitric oxide synthase (NOS) activity that was associated with an increase in the extent of the damage.

Indomethacin is known to induce reactive oxygen metabolites in animal models, which may contribute to mucosal injury (Chattopadhyay et al., 2006). These free radicals also damage the cellular antioxidant enzymes such as gastric mucosal catalase, superoxide dismutase and others, acting as the first line of cellular defense against oxidative injury. This might lead to tissue damage and stomach ulceration (El-Missiry et al., 2001). Indomethacin-induced stomach ulceration was accompanied by severe oxidative stress in gastric tissue causing damage to key biomolecules such as lipids. This was apparent from the stimulated lipid oxidation leading to increased accumulation of gastric mucosal malondialdehyde which results from lipid peroxidation of polyunsaturated fatty acids. 
These biochemical findings were confirmed by histopathological results, as indomethacin showed ulcer formation associated with necrosis and sloughing of the gastric mucosa

Sildenafil is a drug commonly used in the treatment of erectile dysfunction. It inhibits the metabolism of cGMP, resulting in increased relaxation of the smooth muscle surrounding arterioles supplying the human corpus cavernosum (Ross, 1999). The results of the present study showed that sildenafil pretreatment, before INDO, decreased gastric acidity, led to reductions in $\mathrm{UI}$ values and yielded a high preventive index. The explanation of the beneficial role of sildenafil may be attributed to that it has been demonstrated that inhibition of phosphodiesterase inhibitor-5 will cause a marked improvement in gastric blood flow. This may be attributed to an increase in the level of nitric oxide (NO) which is a potent vasodilator. The increase in NO level is attributed to the accumulation of intracellular cGMP after the inhibition of the enzyme phosphodiesterase inhibitor- 5 by sildenafil with resultant block to the pathway of NO degradation (Aziret et al., 2014). Thus, the results of the present study demonstrate that SILD, acting via NOdependent mechanisms. Our study showed that sildenafil reduced malondialdyhyde (MDA) content. Decrement in MDA contents might be due to induction of superoxide dismutase and catalase activities since sildenafil significantly increased the activities of these enzymes (Fernandes et al., 2008; Hotston et al., 2008).

The present study has been shown that sildenafil significantly reduced the content of pro-inflammatory cytokines TNF- $\alpha$. The reduced TNF-acontent may be attributed to reduced hypoxia following improvement of local blood flow caused by NO. Hypoxia is a well-known factor to induce the expression of proinflammatory cytokines (Ahmed et al., 2012). Also, the histopathological results support the biochemical results.

The qualitative phytochemical analysis of the MO clarified the presence of alkaloids, carbohydrates, proteins, saponins, tannins, triterpenoids, and steroids (Ross, 1999). The flavonoid quercetin present in the leaves is a well-known antiulcer agent (Suzuki et al., 1998). Further, the leaves contain rutin, a flavonoid that has a gastric cytoprotective effect (Casa et al., 2000). Moreover, the leaves of the plant contain steroids such as b-sitosterol and bcarotene, and both of these are known to reduce the development of gastric ulcers (Xiao et al., 1992). The protective activities of these active saponins in $\mathrm{MO}$ are probably due to the activation of mucous membrane protective factors (Satio et al., 1977).

Tannins are used in medicine primarily because of their astringent properties, which are attributed to the fact that they react with the proteins in the layers of tissue with which they come into contact. Tannins are known to "tan" the outermost layer of the mucosa and to render it less permeable and more resistant to chemical and mechanical injury or irritation (AsuzuandOnu, 1990). It was recorded that these phenolic compounds found in the leaves protect the stomach by many mechanisms including antisecretory activity, cytoprotection, modulation of inflammatory mediators, antioxidative stress defense and enhancement of the levels of antioxidant enzymes in the body (Hamedi et al., 2015). MO leaves also contain bioactive compounds capable of inducing antioxidant systems and modulating the expression of genes involved in the inflammatory response (Cuellar et al., 2019). The results of the current study elucidate that consumption of the leaves of Moringa oleifera may be important in the healing of ulcers in patients suffering from peptic ulcer disease.

The most reduction in the MDA level was recorded in Moringa-pretreated rats and a subsequent decreased in the severity of tissue damage. This could be explained by that Mo reduces lipid peroxidation and normalize antioxidant enzyme levels (Agrawal et al., 2015). Also, Moringa has high antioxidant activity due to its high content of bioactive polyphenols (Verma et al., 2009).

The present study showed that indomethacin enhances caspase-3 activation which leads to epithelial cell apoptosis. Indomethacin produces its effects on apoptogenic signal propagation through the induction of TNF- $\alpha$ 
(Wallach, 1997). Sildenafil may be able to inhibit these apoptogenic processes by the inhibition of TNF- $\alpha$ as it reduces hypoxia following improvement of local blood flow caused by NO.

The effects of sildenafil, Moringa and their combination on the indomethacin-induced apoptosis in rats stomach are depicted by the immunohistochemical results. However, the moderate reduction in $\mathrm{pH}$ and ulcer score results observed in rats treated with the combination of Sildenafil and Moringa compared to Sildenafil group reflecting chemical/physical interaction between both of theme leading to lack of potentiation or synergistic action between both of theme.

\section{CONCLUSION}

Both Sildenafil and Moringa have a protective effect on the experimentally induced gastric ulcer. However, the sildenafil effect was much more potent than Moringa leaves and the combination.

\section{Conflict of interest}

The authors declared no conflict of interest.

\section{REFERENCE}

Ahmed OM, Afifi A, Ali TM, Ramadan SA, and Mahmoud AM, (2012): Ameliorative effects of sildenafil in acetic acid-induced chronic colitis in rats. Life Sci. Journal. 9(1): 354-361.

Appleyard CB, McCafferty DM, Tigley AW, SwainMG, and Wallace JL (1996): Tumor necrosis factor mediation of NSAID-induced gastric damage: role of leukocyte adherence.American Journal of Physiology-Gastrointestinal and Liver Physiology; 270(1): G42-G48.

Araujo DA, Takayama C, De-Faria FM, Socca EA, Dunder RJ, Manzo LP, and Souza-Brito AR (2011): Gastroprotective effects of essential oil from Protiumheptaphyllum on experimental gastric ulcer models in rats. Revista Brasileira de Farmacognosia; 21(4): 721-729.

Asuzu IU,andOnu OU (1990): Anti-ulcer activity of the ethanolic extract of Combretumdolichopetalum root. International Journal of Crude Drug Research, 28(1): 27-32.

Aziret M, Irkorucu O, Reyhan E, Erdem H, Das K, Ozkara S, and Deger KC (2014): The effects of vardenafil and pentoxifylline administration in an animal model of ischemic colitis. Clinics; 69(11): 763-769.
Bauer H, Jung T, Tsikas D, Stichtenoth DO, Frolich JC, and Neumann C (1997): Nitric oxide inhibits the secretion of T-helper 1- and T-helper 2associated cytokines in activated human $\mathrm{T}$ cells. Immunology; 90(2):205-211.

Bech PL, Xavier R, Lu N, Nanda NN, Dinauer M, Podolsky DK, and Seed B (2000): Mechanisms of NSAID-induced gastrointestinal injury defined using mutant mice. Gastroenterology; 119(3):699-705.

Bichi MH, Agunwamba JC, and Muyibi SA (2012): Kinetics of water disinfection with Moringaoleifera seeds extract. Journal of Environmental and Earth science;(2): 58-69.

Bortolotti M, Mari C, Lopilato C, LaRovere L, and Miglioli M (2001): Sildenafil inhibits gastroduodenal motility. Alimentary pharmacology and therapeutics. 15(2):15761.

Bou-Abboud CF, Wayland H, Paulsen G, and Guth PH (1988): Microcirculatory stasis precedes tissue necrosis in ethanol-induced gastric mucosal injury in the rat. Digestive diseases and sciences; 33(7): 872-877.

Casa CL, Villegas I, Lastra CA, Motilva V, and Calero MJM (2000): Evidence for protective and antioxidant properties of rutin, a natural flavone, against ethanol induced gastric lesions. Journal of ethnopharmacology; 71(12): 45-53.

Chattopadhyay I, Bandyopadhyay U, Biswas K, Maity P, and Banerjee RK (2006): Indomethacin inactivates gastric peroxidase to induce reactive oxygen-mediated gastric mucosal injury and curcumin protects it by preventing peroxidase inactivation and scavenging reactive oxygen. Free radical biology and medicine; 40(8):1397-1408.

Chen YL, Le Vraux V, Giroud JP, and ChauvelotMoachon L, (1994): Anti-tumor necrosis factor properties of non-peptide drugs in acute-phase responses. European Journal of pharmacology; 271(2-3): 319-327.

Cryer B, and Mahaffey KW (2014): Gastrointestinal ulcers, role of aspirin, and clinical outcomes: pathobiology, diagnosis, and treatment. Journal of multidisciplinary healthcare; (7): 137.

Cuellar M, Loarca F, Mejia EGD, and Luzardo I (2019): Moringa oleifera Leaves Induced Antioxidant and Phase II Enzymes in a Colitis-associated Colon Carcinogenesis Model (P06-053-19) 3(Suppl 1).

DashputreNL,andNaikwade NS (2011): Evaluation of anti-ulcer activity of methanolic extract of Abutilon indicum Linn leaves in experimental 
rats. International Journal of Pharmaceutical Sciences and Drug Research; 3(2): 97-100.

Dawud FA, Mabrouk MA, Mohammed A, and Umar IA (2014): Effect of vitamins $C$ and $E$ on aspirin induced gastric mucosal damage and oxidative stress. Current Research Journal of Biological Sciences; (6): 36-41.

El-Missiry MA, El-Sayed IH, and Othman Al (2001): Protection by metal complexes with SODmimetic activity against oxidative gastric injury induced by indomethacin and ethanol in rats. Annals of clinical biochemistry ;(38):694-700.

Fernandes M.A, Marques, R. J, Vicente J.A, Santos M.S, Monteiro P, Moreno A. J, andCustódio J. B (2008): Custódio Sildenafil citrate concentrations not affecting oxidative phosphorylation depress $\mathrm{H}_{2} \mathrm{O}_{2}$ generation by rat heart mitochondria. Molecular and cellular biochemistry; (309): 77-85.

Hamaguchi M, Watanabe T, Higuchi K, Tominaga K, Fujiwara Y,and Arkawa T (2001): Mechanisms and roles of neutrophil infiltration in stressinduced gastric injury in rats. Digestive diseases and sciences; 46(12):2708-2715.

Hamedi S, Arian AA, and Farzaei MH (2015): Gastroprotective effect of aqueous stem bark extract of Ziziphusjujuba L. against $\mathrm{HCl} /$ ethanol-induced gastric mucosal injury in rats. Journal of Traditional Chinese Medicine, 35(6): 666-670.

Hogg N, and Kalyanaraman B (1999): Nitric oxide and lipid peroxidation. Biochimica et Biophysica Acta (BBA)-Bioenergetics; 1411(2-3): 378384.

Hotston M, Jeremy J. Y, Bloor J, Greaves N. S, Persad $\mathrm{R}$, Angelini $\mathrm{G}$ and Shukla N (2008): Homocysteine and copper interact to promote type 5 phosphodiesterase expression in rabbit cavernosal smooth muscle cells. Asian journal Androl; (10): 90591.

Karakaya K, Hanci V, Bektas S, Can M, Ucan HB, Emre AU, Tascilar O, Turan IO, Comert M, Irkorucu O, and Cakmak GK (2009): Mitigation of indomethacin-induced gastric mucosal lesions by a potent specific type $\mathrm{V}$ phosphodiesterase inhibitor. World Journal of Gastroenterology: WJG. 15(40):5091.

Kiziltunç A, Gürsan N, andÖren D (2007): The role of sildenafil citrate in the protection of gastric mucosa from nonsteroidal anti-inflammatory drug-induced damage. Turkish Journal of Trauma and Emergency Surgery; 13(4): 268273.

Konturek SJ, Brzozowski T, Majka J, Pytko-Polonczyk J, and Stachura J (1993): Inhibition of nitric oxide synthase delays healing of chronic gastric ulcers. European journal of pharmacology. 239(1-3):215-7.

Kuna L, Jakab J, Smolic R, Raguz-Lucic N, Vcev A, Smolic M (2019): Peptic ulcer disease: a brief review of conventional therapy and herbal treatment options. Journal of clinical medicine, 8(2): 179-197.

Kunkel SL, Wiggins RC, Chensue SW, and Larrick J (1986): Regulation of macrophage tumor necrosis factor production by prostaglandin E2.Biochemical and biophysical research communications; 137(1):404-410.

Lambole V, and Kumar U (2012): Effect of Moringaoleifera Lam. on normal and dexamethasone suppressed wound healing. Asian Pacific Journal of Tropical Biomedicine; 2(1): S219-23.

Levi S, Goodlad RA, Walport MJ, Hodgson HJF, and Lee CY (1990): Inhibitory effect of NSAIDs on mucosal cell proliferation associated with gastric ulcer healing. The Lancet; (336): 840843.

Li YM, Lu GM, Zou XP, Li ZS, Peng GY, and Fang DC (2006): Dynamic functional and ultrastructural changes of gastric parietal cells induced by water immersion-restraint stress in rats. World Journal of Gastroenterology: WJG. 12(21):3368.

Mahmud T, Rafi SS, Scott DL, Wrigglesworth JM, and Bjarnason I (1996): Non-steroidalanti inflammatory drugs and uncoupling of mitochondrial oxidative phosphorylation. Arthritis \& Rheumatism; 39(12): 1998-2003.

Martín MJ, Jiménez MD, and Motilva V (2001): New issues about nitric oxide and its effects on the gastrointestinal tract. Current pharmaceutical design; 7(10): 881-908.

Mbikay M, (2012): Therapeutic potential of Moringaoleifera leaves in chronic hyperglycemia and dyslipidemia: a review. Frontiers in pharmacology; ???3- 24.

Mehta J, Shukla A, Bukhariya V, and Charde R (2011).The magic remedy of Moringaoleifera: an overview. International journal of biomedical and advance research; (2):272278.

Miller T, (1983): Protective effects of prostaglandins against gastric mucosal damage: current knowledge and proposed mechanisms. American Journal of PhysiologyGastrointestinal and Liver Physiology; 245(5): G601-G623.

Miranda KM, Espey MG, and Wink DA (2001): A rapid, simple spectrophotometric method for simultaneous detection of nitrate and nitrite. Nitric oxide; 5(1): 62-71. 
Mitsushige S, Takahisa F, Naohito S, Akiko N, Fang X, and Masayoshi K (2007): Different effects of polymorphisms of tumor necrosis factoralpha and interleukin-1 beta on development of peptic ulcer and gastric cancer. Journal of gastroenterology and hepatology; 22(1):5159.

Naito Y, Yoshikawa T, Kaneko T, linuma S, Nishimura S, Takahashi S, and Kondo M (1993): Role of oxygen radicals in indomethacin-induced gastric mucosal microvascular injury in rats. Journal of clinical gastroenterology; (17): 99103.

Pal S K, Mukherjee PK, and Saha BP (1995): Studies on the antiulcer activity of Moringaoleifera leaf extract on gastric ulcer models in rats. Phytotherapy Research; 9(6):463-5.

Pastoris O, Verri M, Boschi F, Kastsiuchenka O, Balestra B, Pace F, Tonini M,and Natale G (2008): Effects of esomeprazole on glutathione levels and mitochondrial oxidative phosphorylation in the gastric mucosa of rats treated with indomethacin.Naunyn-Schmiedeberg's archives of pharmacology; 378(4): 421-429.

Pawlik T, Konturek PC, Konturek JW, Konturek SJ, Brzozowski T, Cześnikiewicz M, Plonka $M$, Bielanski W, and Areny $\mathrm{H}$ (2002): Impact of Helicobacter pylori and nonsteroidal antiinflammatory drugs on gastric ulcerogenesis in experimental animals and in humans. European journal of pharmacology; 449(12):1-5.

Ross IA, (1999): Medicinal plants of the World. New Jersey, Humana Press; 234-235.

Saito H, Lee Y, Takagi K, Shibata S, Shoji J, and Kondo N (1977): Pharmacological studies of Panacis japonicirhizoma. I. Chemical and Pharmaceutical Bulletin, 25(5): 1017-1025.

Salvemini D, Misko TP, Masferrer JL, Seibert K, Currie MG, and Needleman P (1993): Nitric oxide activates cyclooxygenase enzymes. Proceedings of the National Academy of Sciences; 90(15):7240-7244.

Sameh Saber, Rania M Khalil, Walied S Abdo, Doaa Nassif, Eman El-Ahwany (2019): Olmesartan ameliorates chemically-induced ulcerative colitis in rats via modulating NFKB and Nrf2/HO-1 signaling crosstalk. Toxicology and Applied Pharmacology; 364, 120-132.

Samini M, Moezi L, Jabarizadeh N, Tavakolifar B, Shafaroodi H, and Dehpour A (2002): Evidences for involvement of nitric oxide in the gastroprotective effect of bromocriptine and cyclosporin a on water immersion stressinduced gastric lesions. Pharmacological research; 46(6):519-523
Santucci L, Fiorucci S, Di Matteo FM, and Morelli A (1995): Role of tumor necrosis factor alpha release and leukocyte margination in indomethacin-induced gastric injury in rats. Gastroenterology; 108(2):393-401.

Sivaraman D, and Muralidharan P (2011): Cytoprotective effect of Morinda tinctoria Roxb. against surgical and chemical factor induced gastric and duodenal ulcers in rats. Ulcers; 2011.

Suvarna SK, and Layton C (2013): Bancroft's Theory and Practice of Histological Techniques. Churchill Livingstone. Elsevier Aughey E, Frye FL. Comparative veterinary histology. Manson publishing; 21(2010): 173-186.

Suzuki Y, Ishihara M, Segami T, and Ito M (1998): Anti-ulcer effects of antioxidants, quercetin, a-tocopherol, nifedipine and tetracycline in rats. The Japanese Journal of Pharmacology; 78 (4): 435-441.

Swarnakar S, Ganguly K, Kundu P, Banerjee A, Maity $P$, and Sharma AV (2005): Curcumin regulates expression and activity of matrix metalloproteinase 9 and 2 during prevention and healing of indomethacin-induced gastric ulcer. Journal of Biological Chemistry; 280(10):9409-9415.

Tanaka J, and YudaY (1996): Lipid peroxidation in gastric mucosal lesions induced by indomethacin in rat. Biological and Pharmaceutical Bulletin;19(5): 716-720.

Tang RS, and Chan FK (2012): Therapeutic management of recurrent peptic ulcer disease. Drugs; 72(12), 1605-1616.

Tripp MA, and Tepperman BL (1995): Effect of nitric oxide on integrity, blood flow and cyclic GM levels in the rat gastric mucosa: modulation by sialoadenectomy. British journal of pharmacology; 115(2):344-348.

Tsukimi Y, and Okabe S (2001): Recent advances in gastrointestinal pathophysiology: role of heat shock proteins in mucosal defense and ulcer healing. Biological and Pharmaceutical Bulletin; 24(1): 1-9.

Vaananen PM, Meddings JB, and Wallace JL (1991): Role of oxygen-derived free radicals in indomethacin-induced gastric injury. American Journal of PhysiologyGastrointestinal and Liver Physiology; 261. (3):G470-G475.

Verma VK, Singh N, Saxena P, and Singh R (2012). Anti-ulcer and antioxidant activity of Moringaoleifera (Lam) leaves against aspirin and ethanol induced gastric ulcer in rats. International Research Journal of Pharmaceuticals; 2(2): 46-57. 
Wallace JL, (1997): Nonsteroidal anti-inflammatory drugs and gastro enteropathy: the second hundred years. Gastroenterology. Mar 1; 112(3):1000-16.

Wallace JL, McKnight W, Reuter BK, and Vergnolle N (2000): NSAID-induced gastric damage in rats: requirement for inhibition of both cyclooxygenase 1 and 2. Gastroenterology. 119(3):706-14.

Wallach D, (1997): Cell death induction by TNF: a matter of self-control. Trends in Biochemical Sciences; 22(4):107-109.

Wei XM, Heywood GJ, Di Girolamo N, and Thomas PS (2003): Nicorandil inhibits the release of TNF alpha from a lymphocyte cell line and peripheral blood lymphocytes. International immunopharmacology; 3(12):1581-1588.

Xiao M, Yang Z, Jiu M, You J, and Xiao R (1992): The antigastroulcerative activity of b-sitosterol-bD-glucoside and its aglycone in rats. Hua xi yike da xuexuebao= Journal of West China University of Medical Sciences= Huaxiyikedaxuexuebao; 23(1): 98-101.
Yoshioka T, Kawada K, Shimada T, and Mori M (1979): Lipid peroxidation in maternal and cord blood and protective mechanism against activated-oxygen toxicity in the blood. American Journal of obstetrics and gynecology, 135(3): 372-376.

Agrawal N , Nirala S, Shukla S and Mathur R (2015): Co-administration of adjuvants along with Moringa oleifera attenuates berylliuminduced oxidative stress and histopathological alterations in rats. Pharmaceutical biology; 53(10), 14651473.

Verma A, Vijayakumar M, Mathela C and Rao C (2009): In vitro and in vivo antioxidant properties of different fractions of Moringa oleifera leaves. Food and Chemical Toxicology; 47(9), 2196-2201. 


\section{Egyptian Association for Cancer Research (EACR)}

http://eacr.tanta.edu.eg/

EACR is an NGO society that was declared by the Ministry of Social Solidarity (Egypt) No. 1938 in 19/11/2014 based on the initiative of Prof. Mohamed Labib Salem, the current Chairman of EACR. EACR aims primarily to assist researchers, in particular young researchers in the field of cancer research through workshops, seminars and conferences. Its first international annual conference entitled "Anti-Cancer Drug Discovery" was successfully organized in April 2019 (http://acdd.tanta.edu.eg). Additionally, EACR aims to raise the awareness of the society about the importance of scientific research in the field of cancer research in prediction, early diagnosis and treatment of cancer. EACR is also keen to outreach the scientific community with periodicals and news on cancer research including peer-reviewed scientific journals for the publication of cutting-edge research. The official scientific journal of EACR is "International Journal of Cancer and biomedical Research (IJCBR: https://jcbr.journals.ekb.eg) was successfully issued in 2017 and has been sponsored by the Egyptian Knowledge Bank (EKB: www.ekb.eg).

\section{EACR Chairman,}

Prof. Mohamed Labib Salem, PhD

Professor of Immunology

Faculty of Science, Tanta Universiy, Egypt 


\section{Editor-in-Chief}

Mohamed Labib Salem, PhD

Tanta University, Egypt

\section{Managing Editor}

Nehal Elmashad, MD

Tanta University, Egypt

Nabil Mohy Eldin, PhD

Kafrelsheikh University, Egypt

Doaa Al-Ghareeb, PhD

Alexandria University, Egypt

Abdel-Aziz Zidan, PhD

Damanhour University, Egypt

Wesam Meshrif, PhD

Tanta University, Egypt

Rasha Eraky, MD

Tanta University, Egypt

\section{Associate Editor}

Hesham Tawfik

Tanta University, Egypt

Mostafa El-Sheekh

Tanta University, Egypt

Yousry Albolkiny, PhD

Tanta University, Egypt

Gamal Badr

Assuit University, Egypt

Elsayed Salim

Tanta University, Egypt

Essam Elshiekh

Tanta Cancer Center, Egypt

\section{Editorial Board}

\author{
Alberto Montero \\ Taussig Cancer Center, \\ Cleveland, USA \\ Marcela Diaz \\ Cleveland Clinic Foundation, USA \\ Yi Zhang \\ Zhengzhou University, China \\ Shengdian Wang \\ Chinese Academy of Sciences, \\ China \\ Faris Alenzi \\ Prince Sattam bin Abdulaziz \\ University, KSA \\ Mark Robunstein \\ Medical University of South \\ Carolina, USA \\ Mamdooh Ghoneum, DSc \\ Charles Drew University of \\ Medicine \& Science, USA
}

Natarajan Muthusamy, DVM

The Ohio State University, USA

Hideki Kasuya MD, PhD,

FACS

Nagoya University, Japan

Sherif El-Khamisy, MD

Sheffield University, UK

Mohamed Abou-El-Enein,

MD

Charité Universitätsmedizin

Berlin, Germany

Alaa Eldin Almostafa, MD

McGill University, Canada

Amr Amin

United Arab Emirates

University, UAE

AbdeIRahman Zekri

National Cancer Institute, Egypt

Mohamed Attia, MD

Tanta University, Egypt

Mohamed Elshanshory, MD

Tanta University, Egypt

Hussein Khamis

Alexandria University, Egypt

Magdy Mahfouz

Kafr Elsheikh University, Egypt

Ehab Elbedewey

Tanta University, Egypt

Abeer Badr

Cairo University, Egypt

Nadia Hamdy, PharmD

Ain Shams University, Egypt

Ibrahim El-Sayed

Menoufia University, Egypt

Tarek Aboul-Fadl, PharmD

Assiut University, Egypt

Mohamed Noureldin

Banaha University, Egypt

Haiam Abou Elela

National Institute of

Oceanography and Fisherie,

Egypt

Sameh Ali, MD

Nationa Liver Institute, Egypt

Maha EL-Demellawi

City for Scientific Research \&

Technology Applications, Egypt

Desouky A Abd-El-Haleem

City for Scientific Research \&

Technology Applications, Egypt
Ashraf Tabll

National Research Center, Egypt

Wael Lotfy, MD

Alexandria University, Egypt

Olfat Gadallah, MD

Tanta University, Egypt

Nahla Shoukry

Suez University, Egypt

Medhat Eldenary

Tanta University, Egypt

Nagla Sarhan, MD

Tanta University, Egypt

Naglaa Fathy, MD

Zagazik University, Egypt

Azza Hasan Mohamed Menufia University, Egypt

Nanees Gamal Eldin

Tanta University, Egypt

Mohamed Mansour, UK

Sabbah Hammoury

Alexandria Ayadi Almostaqbal

Oncology Hospital, Egypt

Nehal Aboulfotoh

Zewail City for Science and

Technology, Cairo, Egypt

Amir Elkhami

Galaxo, San Francisco, USA

Rabab Khairat

National Research Center,

Giza, Egypt

Ahmed Alzohairy

Zagazi University, Egypt

Wgady Khalil

National Research Center, Egypt

Sayed Bakry

Alazhar University, Egypt

Mohamed Ghanem, MD

Kafr Elshikh University, Egypt

Mohamed Salama, MD

Mansoura University, Egypt

Mona Marie, MD

Alexandria University, Egypt

\section{For more information, contact}

Hamdi Kandil

Tanta University, Egypt

Email: ljcbr100@gmail.com 